\title{
Municipal Milk Supply in Germany
}

\section{The Remarkable Institution of the City of Dresden}

\section{By Dr. Alfred Gradenwitz}

THERE is a general tendency in most of the cities of Germany to place the most important branches of public service under municipal control. Another step toward this growing centralization has been taken by the city of Dresden, where a large institution has been founded to handle the milk supply for the population. This institution, which is the largest of its kind in Germany, may be held up as a model in point of equipment, cleanliness and elegance. Every condition for the proper preservation of milk and its products has been fulfilled with scrupulous care Such centralization offers very particular advantages in the handling of so important a staple food material as milk. Every producer has, as it were, a share in the ownership of the central plant, and therefore take
While it is mainly intended to supply the city of Dresden with high-grade unskimmed milk, the municipal dairy also has ample provision for working skimmed milk into curds and cheese, churning butter, etc. The basement contains the churning hall and cold storage room, as well as accommodations for the manufacture of cheese, cream and ice. The central pumping plant is also located here. The churning hall is a well-lighted room of imposing size, thoroughly coled and ventilated. The walls are lined with neat Dutch tiles. The churns are of the Holstein type, and there is a granite butter-kneading machine, in which the buttermilk is pressed out of the butter. The churning tables are of Belgian marble, and the floor is laid with slabs. The butter is prac- various utensils, vessels, bottles, etc. The water is drawn from a well 148 feet deep and capable of rais ing 1,320 gallons of excellent water per hour. On the ground floor is located the immense receiving room which impresses one most favorably by its bright and cheerful appearance and its scrupulous cleanliness. After the milk has been received from the producers, it is separated into two lots, that to be sold un skimmed and milk to be skimmed. Each of these is collected in a separate reservoir. The rich milk thence conveyed by purs to a raised tank, whence it flows by gravity to the centrifugal purifier, the pasteurizer, refrigerator and cold tank. From the last the milk is drawn into bottles and vessel which are then hermetically sealed.

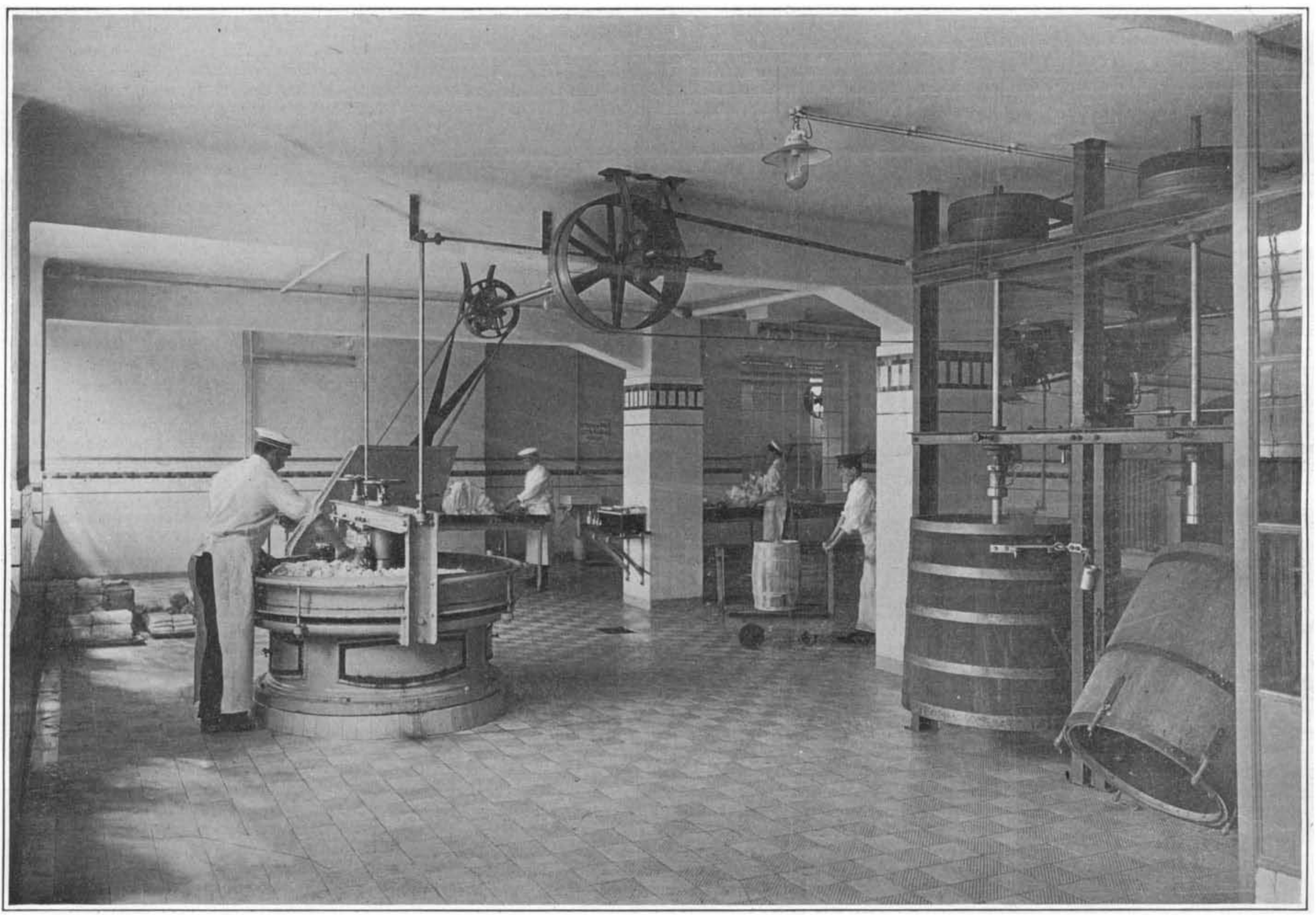

THE CHURNING KOON

a keen interest in its prosperity; and inasmuch as prices are fixed according to the fat contents of the milk, he will obviously put forth his best efforts to supply a product as rich as possible, thus improving the output of the plant and thereby increasing to the maximum attainable the bonus distributed among the members of the producers' association.

It is a matter of common knowledge that milk, under certain internal and external influences, is sus ceptible of undergoing various transformations. If allowed to stand, it becomes covered with a yellow layer of sweet cream, which is merely a collection of fatty particles, and which is converted, by churning, into butter, leaving a residual liquid called butter milk. The fact that milk is liable to turn sour is ascribable to the conversion of its sugar into lactic acid, and as this process depends on the presence of acid, and as this process depends on the presence of oxygen (air) and micro-organisms, the decompition prevented by a cold or hot treatment or a combination of both. Actual boiling, as practiced in the household, is noither necessary nor profitable, as the alterations thereby induced in the milk tend to reduce Its nutritive value. tically untouched by human hands until it comes to be cut into pieces. It is kept absolutely fresh in three large well-cooled storage rooms. There is a cream room with two large tipping tanks for tempering and acidulating the cream, and a special bottling room for the buttermilk. The hall in which the cheese is made is illuminated with dim blue light, as this has been found to be the best means of keeping out flies and other pests. The ice plant works on the carbonic acid process, and at the same time furnishes the cold which is $d$ to be cooled. The refrigerating plant has a capacity of 240,000 B. T. U. per hour, and serves a threefold purpose, namely, for refrigerating the milk and cream to be sold, for generating ice, and for cooling the milk and butter stores. The ice is made by immersing in cold brine sheet metal vessels filled with water. The ice blocks so prepared are passed directly through windows to the delivery vans serving for transport of the products to the consumers and to the branch stations.

Another noteworthy installation located in the base ment is the pumping plant, which amply covers the needs of the total water consumption for washing the
The milk to be skimmed undergoes a similar sequence of operations. It is raised to an elevated tank, whence it flows through a pre-heater to a separator in which the separation into skimmed milk and cream takes place. Both products are passed through pasteurizers, whence they flow through coolers into storage tanks. The cream is then divided, one portion being stored in tanks for sale, while another passes to the cream-maturing tubs of the churn passes to the cream-maturing tubs carried off to the cheese tubs in the basement. An important feature of the arrangement thus described is that the milk is pumped only once. This greatly facilitates its sanitary manipulation, so that a milk practically free from microbes is obtained. Special attention is bestowed upon the supply of infants' milk, which is obtained under special measures of precaution from the stables of the veterinary school. This tion from the in the basement and equipped with all the necessary apparatus.

Adjoining the hall is a room in which all the vessels used in transporting the milk are cleansed with scrupulous care. The method employed is to soak the 
tin cans in hot soda solution, steaming them, and rinsing in fresh water. The bottles are passed through a special machine which cleanses them both inside and out. The plant has a capacity of 4,500 bottles per hour.

The engine room contains two steam engines, one of 100 horse-power capable of furnishing the entire energy required for operating the plant, and a smaller 25 horse-power unit for reserve. The two engines can also be worked concurrently. The exhaust steam is utilized for heating water for rinsing and washing etc. The condensed steam is collected and fed back to the boiler. There are two double-flue boilers, with to the boller. There are two doublefue bollors, with a heating surface of 54 been so designed that their capacity may be doubled at some future date. When working. at its normal capacity the plant will skim 990 gallons per hour, and at the same time turn out for sale an equal amount of rich milk, thus giving an aggregate output of 1,980 gallons per hour.

The salesroom is located on the ground floor and is a perfect model of cleanliness. Adjoining it is a terrace with seating accommodations for customers who come in to drink milk on the premises. ized with advantage by placing in it an elevated cold water tank, fed from a special pumping plant.

The dairy producers who supply the milk to this central plant have to conform to most stringent regulations drawn up in accordance with the requirements of hygiene.

The 1911 Convention of the American Railroad Master Mechanics Association By Reginatd GoRDon.

The American Railway Master Mechanics' Association held its 44th annual convention at Atlantic City, N. J., on the 14th, 15th and 16th of June. As is general!y known, the proceedings of this body represent the yearly progress of the motive power departments of the railways of the United States and Canada. Topics for investigation and report are assigned to committees, the members of which secure the data and report upon them at the next annual convention. The work of the Association has led to valuable results, has assisted tremendously toward the standardizing of the design and construction of locomotives: and in conjunction with the laboratory of Purdue and other technical institutions, is able to supplement service
During the past three years, several types of mo chanical stokers were built and tried out in road service. Many circumstances existed to prejudice railroad men against their use. Liability to get out of order, unfamiliarity on the part of the firemen with the details and with the efficient management of these devices, the fact that some types required the coal to be shoveled into a receiver or hopper, thus still involving severe labor; in addition to which, the very fact that the mechanical stoker could feed more coal than the human stoker, and so increased the coal consumption of the locomotive, all combined to make motive power officials act cautiously, and give, up to this year, only partial indorsement of the machines for actual road work. At the recent convention, however, the report upon this subject brought out the fact that the machines have been simplified in design and strengthened in construction; that on roads where firemen are instructed in their use and taught how to take care of them and keep them in working order on the road, they are regarded as successful, because they feed the coal as fast as demanded by the work the locomotive is doing, maintain the steam pressure, and for these very reasons, haul a greater tonnage

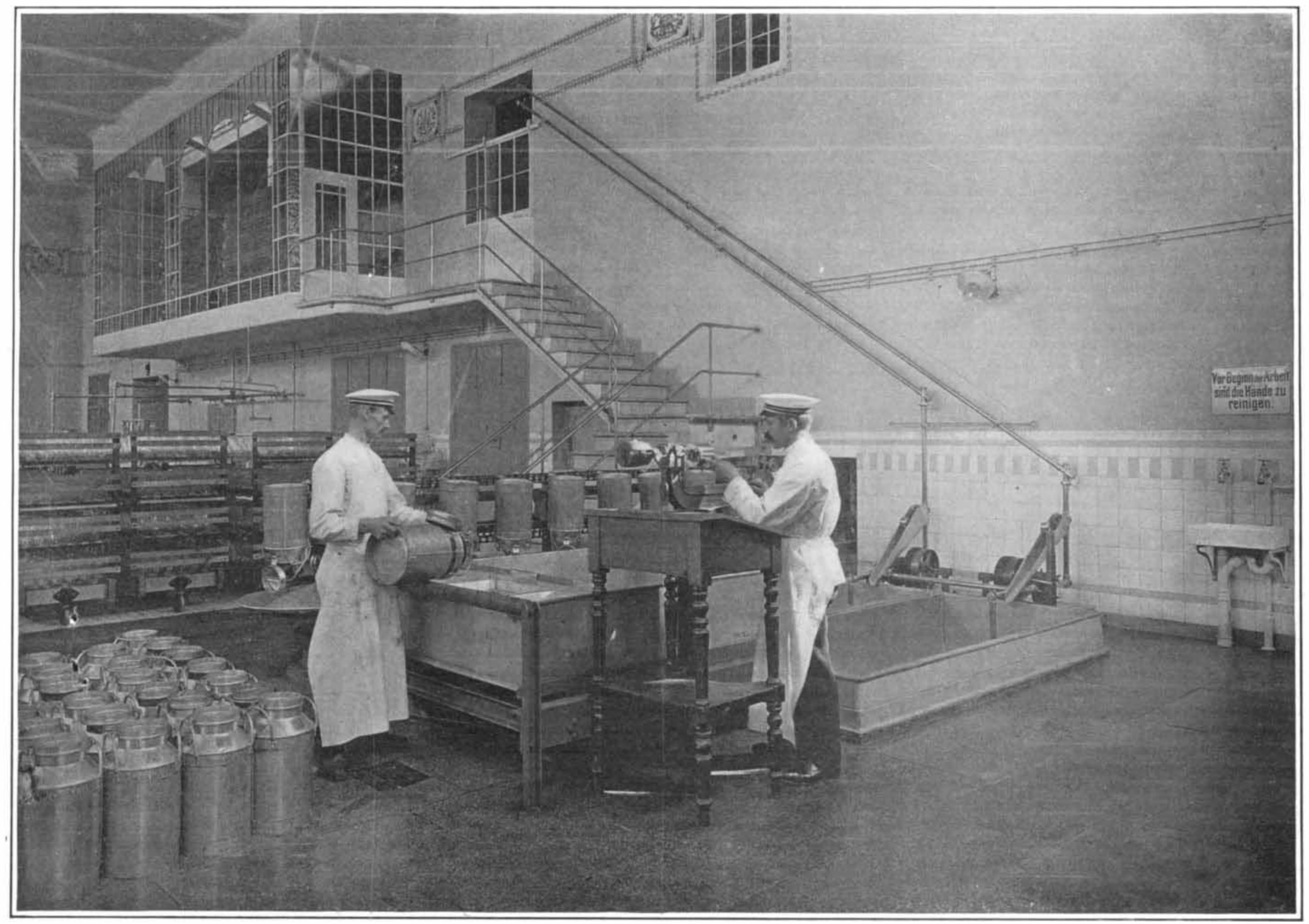

THE ROOM IN WHICH THE SHIPMENTS OF MILK ARE RECEIVED

MUNICIPAL MILK SUPPLY IN GERMANY

The rooms containing the centrifugal snachine skimmers and other apparatus used in working up the milk are situated over the cold storage room. Th three coolers (one each for unskimmed milk, skimme milk and cream) are located on a glass-inclosed balcony in the receiving hall, and are thus completely shut off from outside air. This arrangement is not only eminently satisfactory from a practical point of view, but in point of fact also presents a very pleasing appearance. A short corridor leads to the laboring appearance. A short corridor leads to the laboratory in which the various tests are carried out. 'Tn office rooms, the director's room, and the conference
hall are located as far as possible from the somewhat noisy dairy service.

There are a number of rooms set apart for the em ployees, operators, and elaborate bathing and washing accommodation is provided, particular attention to this point being absolutely necessary if the hig the the pork is to be to the work is to be maintained. There is also a laundry in which all the
linen used in the institution is washed, dried and linen used

The tower of the milk supply building has been util. results on the road with exact data secured from a locomotive on a testing plant where all facilities for exact observation are available.

The most important topics upon which reports were submitted and discussions held this year were $\mathrm{Me}$ chanical Stokers for locomotives, superheated steam safety appliances and smoke prevention. The need of a mechanical device to help the fireman put coal into the firebox began to make itself felt about four years years ago, when the Mallet articulated compond locoponts, exerting a tractive great as that of the largest consolidation locomotives previously used, and with boilers having upward of 5,000 square feet of heating surface, demand coal at a faster rate than can be shoveled by any human being efficiently and intelligently for more than short periods of time; and to operate such large locomotives at maximum power there must be either two firemen em ployed, which is out of the question on the score of expense and division of responsibility, or a machine provided that will feed the coal into the firebor as last as it can be burned. than a hand fired locomotive of the same type. Cost of maintenance of the stoker is as yet not determined with any exactness.

In one kind of stoker in successful use, the coal is taken from the tender by a mechanical conveyor and pushed into the firebox by a reciprocating device oper. ated by steam cylinders secured under the cab deck. This is the "underfeed" type. The coal, if in lumps, must be broken to proper size by the fireman, and pushed, rather than shoveled, into the conveyor; but pise rom the necessity of adjusting the operation of the stoker engine to the work the locomoti the fireman's labor is not hard; and he can get more ton miles hauled than if he attempted to fire the same locomotive by shovel alone.

In another type of stoker, the coal in the tender is fed into a crusher operated by a sma'l steam engine installed in one of the legs of the tender tank. From this crusher the coal runs down a short incline that terminates in a bucket conveyor secured to the back end of the boiler and extending down under the deck. This conveyor is inclosed in a pipe or conduit, some 7 or 8 inches in diameter, and is also operated by 


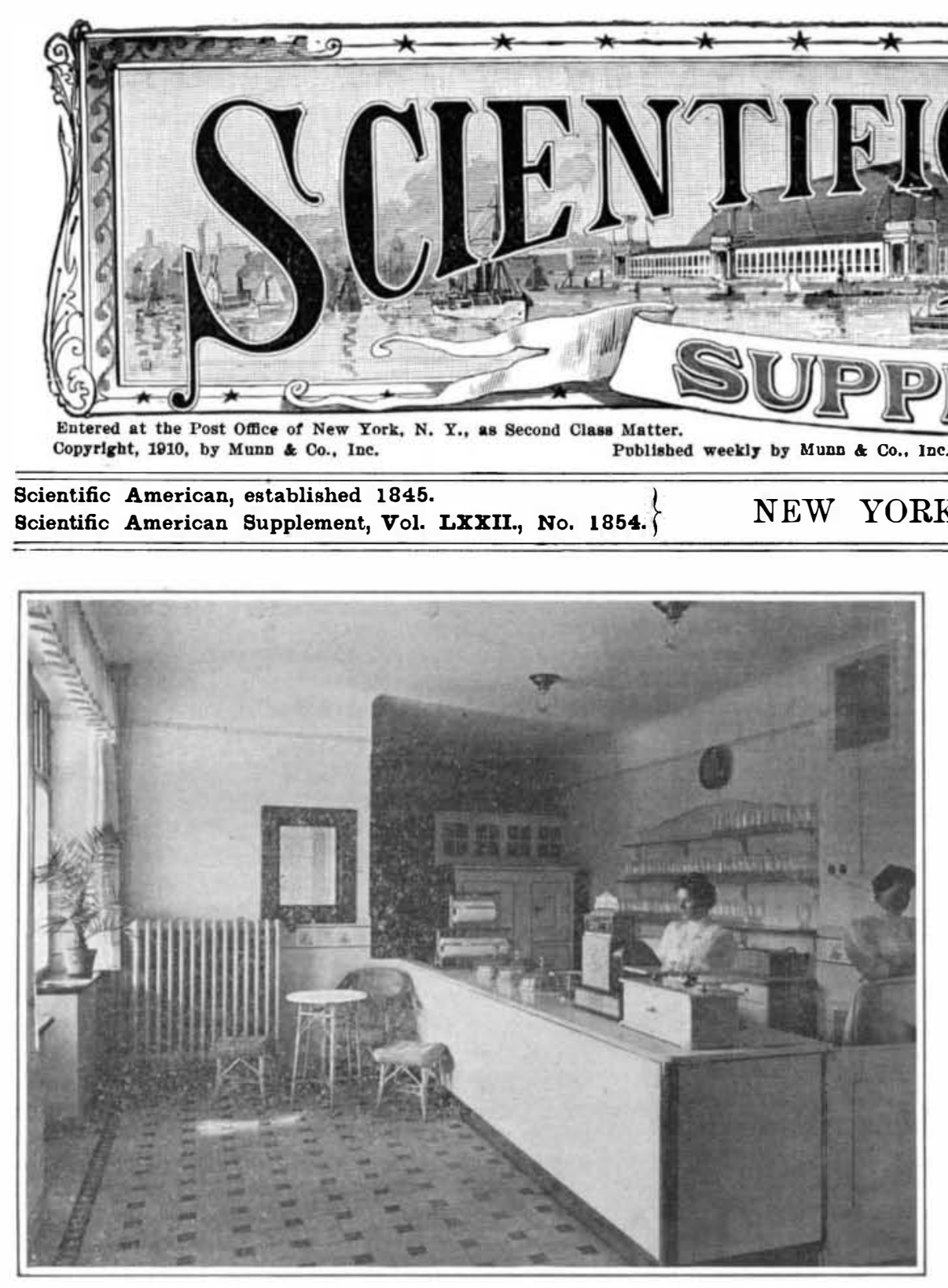

THE SALES ROOM

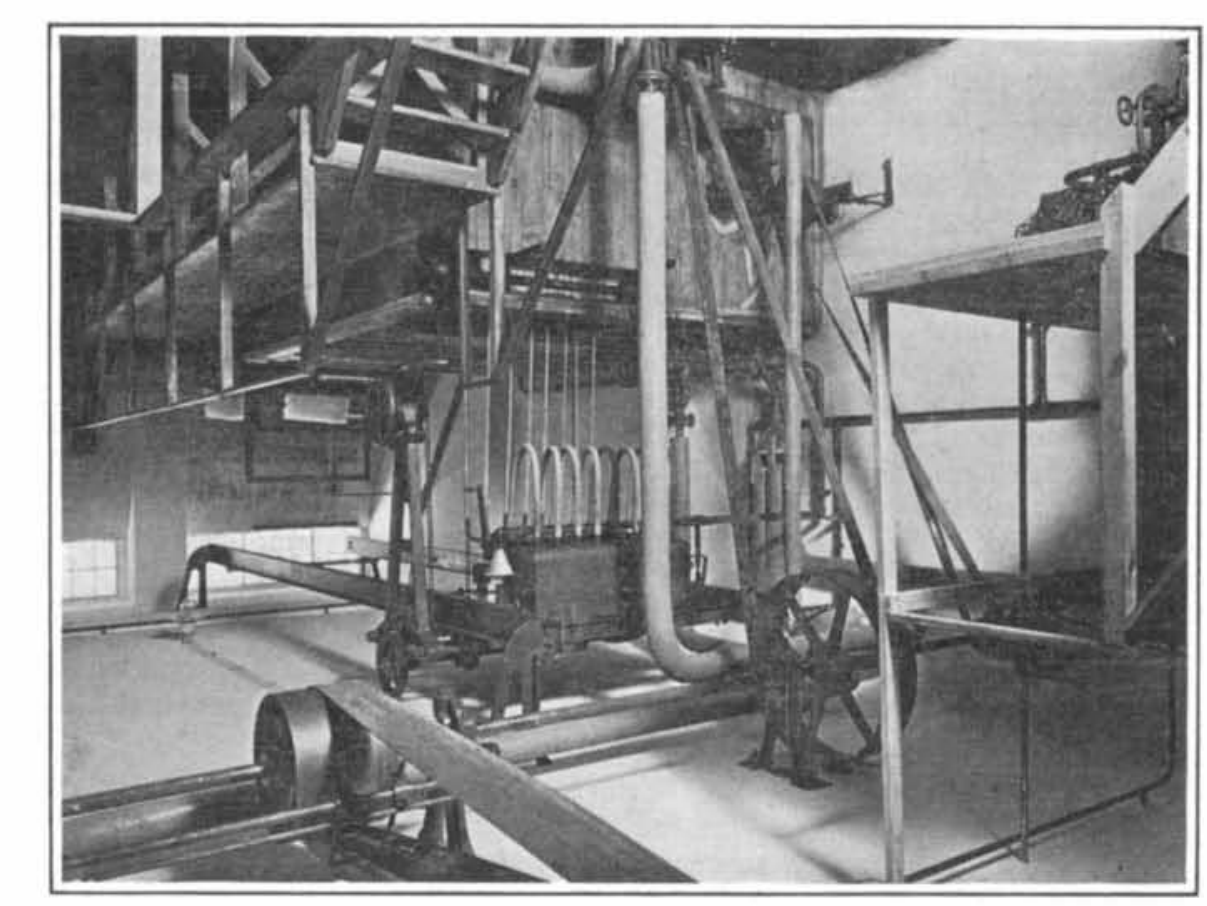

COLd Storage AND Refrigerating PLANT



THE DELIVERY HALL

MUNICIPAL MILK SUPPLY IN GERMANY [SEE PAgE 40] 